Lobell et al. reply - The comments by Basso and Ritchie ${ }^{1}$ are unconvincing for several reasons. First, the main point of our paper $^{2}$ (hereafter referred to as L13) was to gain insight into the mechanism behind the observed negative correlation between extreme heat and yields, a point that Basso and Ritchie do not address. Second, the Agricultural Production Systems Simulator (APSIM) uses a daily time step, and the soilwater balance of the dynamic crop model does account for the amount and timing of rainfall and incorporates algorithms to predict runoff and deep drainage. The timing of rainfall has, of course, an effect on simulated yields, and is one of the many reasons why extreme heat is not a perfect predictor of yields.

Third, they claim that estimates of potential water demand in APSIM are too high, and report values for Penman evapotranspiration (ET) that are all below $6 \mathrm{~mm}$. It is unclear what their table purports to show, or why they choose $15 \mathrm{MJ} \mathrm{m}^{-2}$ radiation for Penman when an assumption of $40 \mathrm{~g} \mathrm{~m}^{-2}$ for potential growth in APSIM would correspond to much higher radiation levels of about $25 \mathrm{MJ} \mathrm{m}^{-2}$. In addition, contrary to the claim made by Basso and Ritchie, many studies have reported ET in maize fields of $10 \mathrm{~mm}$ or more per day. Howell et al. report ${ }^{3}$ Penman-Monteith calculated values of $12 \mathrm{~mm}$ for hightemperature and -radiation conditions. In addition, Piccinni et al. note ${ }^{4}$ that based on large field lysimeter studies, crop water requirements for well-watered maize are 1.2 times greater than the Penman-Monteith estimate, even at such high values. The high Penman-Monteith values for high demand (high radiation and temperature) conditions are reinforced by further large lysimeter studies in irrigated maize ${ }^{5}$ that show measured ET rates of greater than $10 \mathrm{~mm}$ per day for a significant part of the crop cycle (for high leaf-area index).

All of these data closely reflect the estimates derived from the algorithms in APSIM. The evidence highlights that the estimate of potential water use is highly dependent on environmental conditions, and the calculations presented by Basso and Ritchie do not compare like with like. The geographical location is not of concern; the issue is the prevailing environment. While location might affect the frequency of conditions, high demand conditions occur throughout the midwest during the growing season and more so in some years.

Note that even if differences existed between the two approaches, these differences are not evidence that one approach is right and the other is wrong. For example, Monteith argued $^{6}$ that transpiration is limited by growth (as reflected in the APSIM approach), rather than vice versa, as reflected in the Penman approach. We would like to see additional modelling groups repeat the analysis of L13; perhaps some will find that their models are less sensitive to extreme heat or more sensitive to rainfall than both APSIM and observations indicate. However, Basso and Ritchie do not provide any such analysis, they provide no evidence to convince us that our analysis overstated the role of vapour-pressure deficit, and they provide no alternative explanation for the observational fact that yields are much more strongly associated with extreme heat than is rainfall.

References

1. Basso, B. \& Ritchie, J. Nature Clim. Change 4, 233 (2104).

2. Lobell, D. B. et al. Nature Clim. Change 3, 497-501 (2013)

3. Howell, T. A. \& Dusek, D. A. J. Irrig. Drain. Eng. 121, 191-198 (1995)

4. Piccinni, G., Ko, J., Marek, T. \& Howell, T. Agr. Water Manage. 96, 1698-1704 (2009)

5. Howell, T., Evett, S., Tolk, J., Schneider, A. \& Steiner, J. in Proc. Int. Conf. Am. Soc. Agri. Eng. (eds Camp, C. R., Sadler, E. J. \& Yoder, R. E.) 158-166 (American Society of Agricultural Engineers, 1996)

6. Monteith, J. J. Hydrol. 100, 57-68 (1988).

David B. Lobell ${ }^{\star \star}$, Graeme L. Hammer ${ }^{2}$ Greg McLean ${ }^{3}$, Carlos Messina ${ }^{4}$, Michael J. Roberts ${ }^{5}$, Wolfram Schlenker ${ }^{6}$ 'Department of Environmental Earth System Science and Center on Food Security and the Environment, Stanford University, Stanford, California 94305, USA, ${ }^{2}$ The University of Queensland, Queensland Alliance For Agriculture and Food Innovation, Brisbane, Qld 4072, Australia, ${ }^{3}$ Queensland Department of Agriculture, Forestry, and Fisheries, Toowoomba, QId 4350, Australia, ${ }^{4}$ Pioneer Hi-Bred International, Johnston, lowa 50131, USA, ${ }^{5}$ Department of Economics, University of Hawaii at Manoa, Honolulu, Hawaii 96822, USA, ${ }^{6}$ School of International and Public Affairs, Columbia University, New York, New York 10027, USA.

*e-mail:dlobell@stanford.edu

\title{
CORRESPONDENCE:
}

\section{Temperature and violence}

To the Editor - Academic disputes are often contentious, but 'conflict studies' are especially so ${ }^{1}$. Raleigh et al. criticize ${ }^{2}$ our recent papers ${ }^{3-5}$ for "anchoring a modern form of environmental determinism", claiming that our focus on environmental conditions "removes violence from its local, social and political contexts" and that our results imply that "poor people act violently for natural reasons". Both claims are based on misunderstandings of our work and the methods we employ.

Our findings show that the relationship between extreme temperatures and violence is observed in both rich and poor populations alike ${ }^{5}$ and we have consistently highlighted the importance of socio-economic settings. For instance, we demonstrated that the effects of global climatic variation on civil conflicts in the tropics are lower, but still positive, for relatively richer countries ${ }^{4}$. Similarly, in our meta-analysis of the literature we find the magnitude of the effects of climate anomalies on intergroup conflict to be over three times larger than the magnitude of the effects on interpersonal conflict ${ }^{5}$. This implies that both the local socioeconomic context and the type of conflict being examined are important. Even our earliest work studied how the effects of climate on conflict differed across local economic, political, social, geographic and demographic conditions ${ }^{6}$.
None of this work claims that high temperatures or other climatic variations are necessary or sufficient to trigger violence at any scale. To use an analogy, drunkenness may increase traffic accidents, but not all traffic accidents involve drunk drivers and not all drunk drivers have traffic accidents.

All of us believe that political and economic factors influence the occurrence of conflict. Indeed all of our statistical models acknowledge these factors - as Raleigh and colleagues themselves note. We agree with the sentiment that a complete conceptual model of conflict must include political, social and economic factors in addition to environmental causes. The research community will get there faster by first 